\title{
20. The interagency cycle in sustainability transitions
}

\author{
Ari Jokinen, Jarmo Uusikartano, Pekka Jokinen and \\ Marika Kokko
}

\section{INTRODUCTION}

Agency is conceptualised differently across the social sciences. This chapter responds to recent calls for approaches that problematise the current view of keeping human agency distinct from the material or nonhuman world in sustainability research (e.g., Gumbert, 2020). Our research task is to demonstrate the intertwining of human and nonhuman agency, or interagency as we call it, in the creation of sustainability paths. In this task, we are inspired by environmental policy research, science and technology studies (STS), and research on technology and business ecosystems in sustainability transitions. The normative sustainability goal, which is a deep change in human society for environmental reasons and human well-being, inevitably invokes political stances (Patterson et al., 2017). Thus, instead of defining sustainability as a state or final goal, we define it as a process and 'a compass providing orientation for a journey into an unknown future' (Grober, 2015).

In sustainability research, agency is usually understood as individual or collective human action (Robb, 2010; Shapiro, 2005; van der Heijden et al., 2019). This perspective, in which intentionality and mental representations define the idea of agency, is useful in explaining, for instance, the future-oriented decisions made for sustainability. Considering that agency is a vital element of sustainability and change, a wider understanding of agency is needed. A narrow understanding of agency primarily reflects individuals' or organisations' capacity to act autonomously toward desired outcomes, whereas a broader understanding considers agency to be a propensity of social, sociomaterial and socionatural relations (Page, 2014; van der Heijden et al., 2019). Also, nonhuman agents - such as animals, plants, natural events and more-than-human agents, e.g., laws, technologies, procedures and machines - may be viewed as having agency, or at least affecting humans' agency (van der Heijden et al., 2019; Latham, 2017).

The theoretical substance of agency includes a dichotomy between agency and system. Key literature reviews have shown that studies on sustainability transition tend to prioritise structural changes and pay less attention to 'transition agency' and to the 'politics of transition’ (e.g., Fischer \& Newig, 2016; Meadowcroft, 2011; Patterson et al., 2017; Spaargaren et al., 2012). According to Wittmayer et al. (2017), transition research even lacks a suitable vocabulary to analyse actors' interactions and relations as part of sustainability transition. However, although Geels (2020) has asserted that review papers merely tend to repeat this lack of agency, he notes that conceptual and empirical studies leaning on multi-level perspectives on transitions clearly have progressed in understanding multi-faceted agency.

Sustainability transitions research also has started to identify intermediary actors that speed up change toward transition by facilitating connections and relationships between different 
people or things (e.g., Kivimaa et al., 2019). The emphasis in this research is on intentional human action. The challenge is that, in complex systems, a catalytic change has its own behaviour and cannot be managed or predicted fully. This shows that intentional agency is only one type of agency and often becomes too narrow for understanding sustainability processes. While viewing intentional agency as being central, it seems clear that other basic types of agency are equally relevant to sustainability research. We emphasise in this chapter that both human and nonhuman ${ }^{1}$ actors should be incorporated to understand the emergence of possible sustainability paths.

We develop the concept of interagency as an elemental way to understand nonhuman agency and materiality's influential role in sustainability processes, particularly in the circular economy framework in urban sustainability transitions. Interagency employs both human and nonhuman agency, and it entails forces that guide possible sustainability paths that can be adopted during the process. To illustrate the main argument, we present a case study focussing on a cellulose manufacturing by-product - sedimented zero fibre - as an environmental challenge in the City of Tampere, Finland. In this case, zero fibre's material behaviour and interagency develop through mutual human-nonhuman interactions in the context of strategies and practices of business organisations that aim to turn zero fibre from surplus into resource.

This chapter proceeds as follows. First, it introduces extant research focussing on other-than-human agency and discusses its relevance in sustainability research. A highlighted theoretical outcome is the concept of interagency. After presenting the data and methods for the present empirical case study, we demonstrate how interagency helps increase understanding of processes in which technologies and the material world are central elements in sustainability transitions. It appears that interagency develops in a cycle between humans, material and technologies, opening alternative sustainability paths. We proceed by discussing interagency's dynamics. As we will show, nonhuman agency necessarily contributes to sustainability transitions, thereby highlighting the need for interdisciplinary research and new conceptualisations of agency.

\section{WHY ARE NONHUMAN AGENCY, MATERIALITY AND INTERAGENCY RELEVANT IN SUSTAINABILITY TRANSITIONS?}

The concept of material agency has intensified in importance since the 1990s, particularly in critical social science, anthropology, and STS (e.g., Knappett \& Malafouris, 2008). Scholars who utilise the concept essentially maintain that materials have their own incipient agency and, thus, link the issue of agency to nonhuman nature and its features. The essence of sustainability transition basically is difficult to understand without identifying the pivotal role of materials, things and objects in society. To highlight material agency's significance in sustainability research, we first address two examples of research areas: the circular economy and management and organisation research. After that, we develop the foundation for interagency by examining theoretical approaches to material agency.

The circular economy is a major catalyst for sustainability transition processes affecting various layers in society concurrently. As the major definitions of circular economy emphasise material issues - such as resource input, waste, emissions and energy (e.g., Prieto-Sandoval et al., 2018) - material agency supposedly should be a central research issue. Circular economy 
largely is focussed on materials, e.g., by treating them differently depending on whether they have strong recycling potential (e.g., cardboard); lack systematic reuse (polymers); are by-products that can displace virgin material intake (bitumen made into carpets); or are potentially innovative products that are fully restorative by design and intention (bio-based materials that can be returned to the biosphere) (Ellen MacArthur Foundation, 2014). However, contrary to what might be expected, circular economy studies tend to view human agency as referring typically to governments and companies (Corvellec et al., 2020; Geissdoerfer et al., 2017). This means that circular economy scholars so far have not paid much attention to sociomaterial or nonhuman agency. However, a strong case exists for nonhuman agency: The change toward a circular economy requires reducing the use of materials during production and consumption, as well as experiments in which various types of waste are turned into new resources (see also Hobson, 2016).

In the field of management and organisation research, Hoffman and Georg (2018) have analysed the development of theories on business organisations' efforts to tackle environmental problems during the past 40 years. The major finding was that only partial solutions have been implemented in corporate environmentalism, but even these partial solutions intensify the current environmental crisis, as problems are becoming more complex. Therefore, they concluded that current theories, concepts and research modes in the field should be renewed and aligned fundamentally to confront Anthropocene challenges. For them, the nonhuman world is one of the relevant new lines of research that is required, as business and the material environment are 'an effect and an outcome of the complex entanglements between human and nonhuman actors through which their possibilities to act are negotiated, transformed and translated' (Hoffman \& Georg, 2018, p. 31). Thus, Hoffman and Georg argue for making relationships and entanglements between humans and the nonhuman world the focus of research.

Previous research has developed ideas related to nonhuman agency and collective agency between humans and nonhumans. Placing special emphasis on the nonhuman world, research on decentralised agency incorporates material agency and argues against the human-centred view in which consciousness and intentionality are viewed as an exclusive precondition of agency (Knappett \& Malafouris, 2008). Political theorist Jane Bennett (2010) highlights nonhuman materials' active role in public life. She speaks about 'vibrant matter' as a vital force inherent in material forms. They shape technologies and knowledge generation, pointing out multiple sites of agency beyond the human. Consider asbestos, a hazardous waste with corporeal and economic effects on humans. Asbestos has a powerful nonhuman agency based on material properties, capacities and affordances that make it performative in the activities of construction business, demolition and disposal (partly transferred from Europe to Asia). It always has 'the potential to surprise and to exceed' in material transformations (Gregson et al., 2010). Materials like asbestos have powers to capture humans as much as humans like to think they have the world of things under control. This results in interdependencies between humans and nonhumans.

STS provide conceptual tools for understanding the interaction and close entanglements between humans and the material world in knowledge generation. An early step in that direction was Karin Knorr Cetina's (1997) idea of object of knowledge, i.e., material objects have agency in knowledge generation. In these processes, material objects of knowledge never can be attained fully; they continually acquire new properties and change the ones they have. Knowing also is a distributed practice in agential realism, a theory developed by Karen Barad, who maintains that while humans participate in practices of knowing, they 'do so as 
part of the larger material configuration of the world and its ongoing open-ended articulation' (Barad, 2007, p. 379). This theory's key argument is that physical matter and social reality are co-constituting and interdependent phenomena that produce agency as a material-discursive activity. Matter is not a property of things, but a dynamic and shifting entanglement of relations. As a result, agencies for her are neither human nor nonhuman attributes, but rather ongoing reconfigurations of the world.

The strong entanglements between humans and nonhumans in knowledge generation are also a starting point in the development of actor-network theory, a materialist theory that connects the 'social' with the material in a symmetrical way (Latour, 2005). According to that study's empirical findings, humans in scientific laboratories use tools to make material objects easier to observe and manipulate in an effort to find out what they can and cannot do. In this knowledge-generation action, science, tools and technologies engage in crossing back and forth between objects and representation, during which humans and nonhumans affect each other (Latour, 1987). Here, the agency is dependent not just on the human observer, but rather is built by a whole network, including humans, objects, tools and technologies. The back-and-forth movement in knowledge generation also is supported by Andrew Pickering (1995). His relational ontology between human and material agencies incorporates the concept of a mangle of practice, based on empirical studies of scientific practice and noting that human and material agencies are not pre-given, but rather emerge temporally in practice through a dialectic process of resistance and accommodation. In these theorisations, human and material agencies are mutually and emergently productive with each other in knowledge production.

Finally, sociomaterial research on technology is one aspect in the discussion of decentralised agency. Sociomateriality refers to a relational ontology that presumes that the social and the material inherently are inseparable (Orlikowski \& Scott, 2008). This research avoids giving technology a singular or definitive definition, but rather understands the term as theoretically and historically contingent. Humans and technology have no inherent properties, but shape each other through ongoing interaction, which results in sociomaterial (re)configurations in which relations and boundaries between humans and technologies are not pre-given or fixed, but enacted in recurrent practices. In this relational ontology, 'any distinction of humans and technologies is analytical only, and done with the recognition that these entities necessarily entail each other in practice' (Orlikowski \& Scott, 2008, pp. 455-456). For such engagements, Barad (2007) uses the term 'intra-action' to incorporate the mutual constitution of humans and nonhumans; boundaries between humans and nonhumans are not established naturally, but rather historically co-constructed. Leonardi (2011) supports the historical development of technology as imbrications, i.e., events in which the human and the material are intertwined.

We use the above perspectives on decentralised agency to develop our interagency argument. We define the concept of interagency as a process that employs both human and nonhuman agency, and becomes visible in various reconfigurations between them. The process of interagency arises from engagements between material objects, knowledge generation and technologies. We assume that it takes place in cycles, in which human and nonhuman agency repeatedly affect each other and become integrated in situated events. Several scholars have an idea of a cycle in which a distributed agency is generated, including the concepts of vibrant matter (Bennett, 2010), intra-action (Barad, 2007), back-and-forth movement (Latour, 1987), mangle of practice (Pickering, 1995), sociomateriality (Orlikowski \& Scott, 2008) and imbri- 
cations (Leonardi, 2011). The movement that we call interagency can be found in all these concepts.

In our argument, the cyclical evolution of interagency has three important aspects: (1) humans, technologies and materials that constitute interagency change while generating knowledge of the material world; (2) the constituents of interagency change, when technologies, all of which are sociomaterial, are tested and developed in problem solving; and (3) collective human discourse, including policy making, which affects knowledge generation, technological problem solving and potential sustainability paths that are created during the process (in our view, sustainability paths are patterns of change, not linear or deterministic, but evolving in social-institutional, context-dependent environments; cf. Geels \& Schot, 2007). The resulting interagency is not property or possession of humans or nonhumans, but a relational and emergent entanglement between them. What is interesting in interagency is not an entity itself (an object of knowledge or an object of technological solution), but what it becomes and where it stands in the material-discursive process that gives rise to potential sustainability paths.

\section{CASE: SEDIMENTED ZERO FIBRE IN LAKE NÄSIJÄRVI, TAMPERE}

\section{Case Description}

The City of Tampere, Finland's third biggest city by population, is located inland by Lake Näsijärvi $\left(255 \mathrm{~km}^{2}\right)$. Hiedanranta, on the shores of Lake Näsijärvi, is an old industrial area that the city intends to transform into a new residential area using ambitious principles of urban sustainability. The forest industry used the area in the twentieth and early twenty-first centuries, where a pulp mill legally disposed of zero fibre at the bottom of a bay in Lake Näsijärvi until the 1980s, when it started to burn it. Zero fibre is a by-product of cellulose manufacturing and, as implied by the word 'zero', it is usually viewed as not having business potential or offering further benefits to its producers. However, this traditional way of thinking is changing, and both practitioners and academia are reconsidering zero fibre's value. It is estimated that 1.5 million $\mathrm{m}^{3}$ of sedimented zero fibre are lying around in an area measuring 35 hectares in the bay of Lake Näsijärvi. The sediment, up to $10 \mathrm{~m}$ thick, limits the lake's value for the planned suburban area of 25,000 inhabitants and poses a future risk of greenhouse gas emissions (especially $\mathrm{CO}_{2}$ and $\mathrm{CH}_{4}$ ). Following circular economy principles, the city has started an investigation into whether the fibre could be removed from the bay and utilised as a valuable resource. We use this micro-level transition process for urban sustainability as a representative example of interagency.

\section{Data and Analysis}

We examined the sedimented zero fibre case during the 2018-20 period. To study the case comprehensively, we used a combination of 20 retrospective interviews and real-time ethnographic follow-ups with primary and secondary data (Table 20.1), providing a versatile perspective of the case as a micro-level transition process (see Murto et al., 2020). Starting with a qualitative content analysis of the data, we examined the dynamics of interaction between 
Table 20.1 The data sources used in this study

\begin{tabular}{lll}
\hline Expert interviews & Real-time ethnography & Secondary material \\
\hline Agriculture and forestry & Visiting production facilities & Newspaper articles \\
Biotechnology & Attending workshop discussions & Reports \\
Dredging & $\begin{array}{l}\text { Free-form discussions with key } \\
\text { stakeholders }\end{array}$ & Key stakeholders' seminar presentations \\
& Seminars & \\
Energy services & Attending/having key stakeholder meetings \\
Engineering and design services & on updates concerning the issue & \\
& & \\
Environmental engineering & & \\
Product development, special industrial & & \\
machinery & & \\
Public administration & & \\
Waste management & \\
Wastewater treatment & & \\
\hline
\end{tabular}

human actors, technologies and zero fibre. We repeated the analysis until reaching a clear understanding of the turning points at which agential shifts and continuities took shape in the case. Finally, we used the case study findings to finalise our interagency model.

\section{RESULTS: INTERAGENCY AS A CYCLICAL PROCESS}

The interagency model is presented in Figure 20.1, which illustrates how interagency develops cyclically over time as an interaction between the sedimented fibre, human actors and technologies, eventually leading to the emergence of alternative sustainability paths. The following three steps clarify the process. First, interagency arises when the three constituents (the three circles in Figure 20.1) start their reciprocal interaction in knowledge generation. In this back-and-forth interaction, the sedimented fibre unveils and re-forms its characteristics when responding to human actions and experimentations with different technologies. Second, through continuous repetition, this interagential cycle (the big circle in Figure 20.1) moves to the next step, in which possible utilisation paths and ways to harness the sedimented fibre's potential start to take shape. Third, interagency culminates in the evaluation of the utilisation paths (the centre area in Figure 20.1). The following subsections follow the aforementioned order and explain each of the steps in detail.

\section{Acquiring Knowledge about Sedimented Zero Fibre}

In the sedimented zero fibre case, the City of Tampere thus far has had open-ended aims for the processing of the mass. In the face of uncertainties, the city has ordered several studies on the sedimented fibre, and this ever-growing knowledge guides the analysis of alternatives. The studies that different specialists have conducted have examined spreading, thickness, organic content and contaminants in the fibre. In this close knowledge-generation process in which humans, fibre and technologies affect each other, the fibre reveals its detailed characteristics over time through experiments (see the three circles in Figure 20.1). 


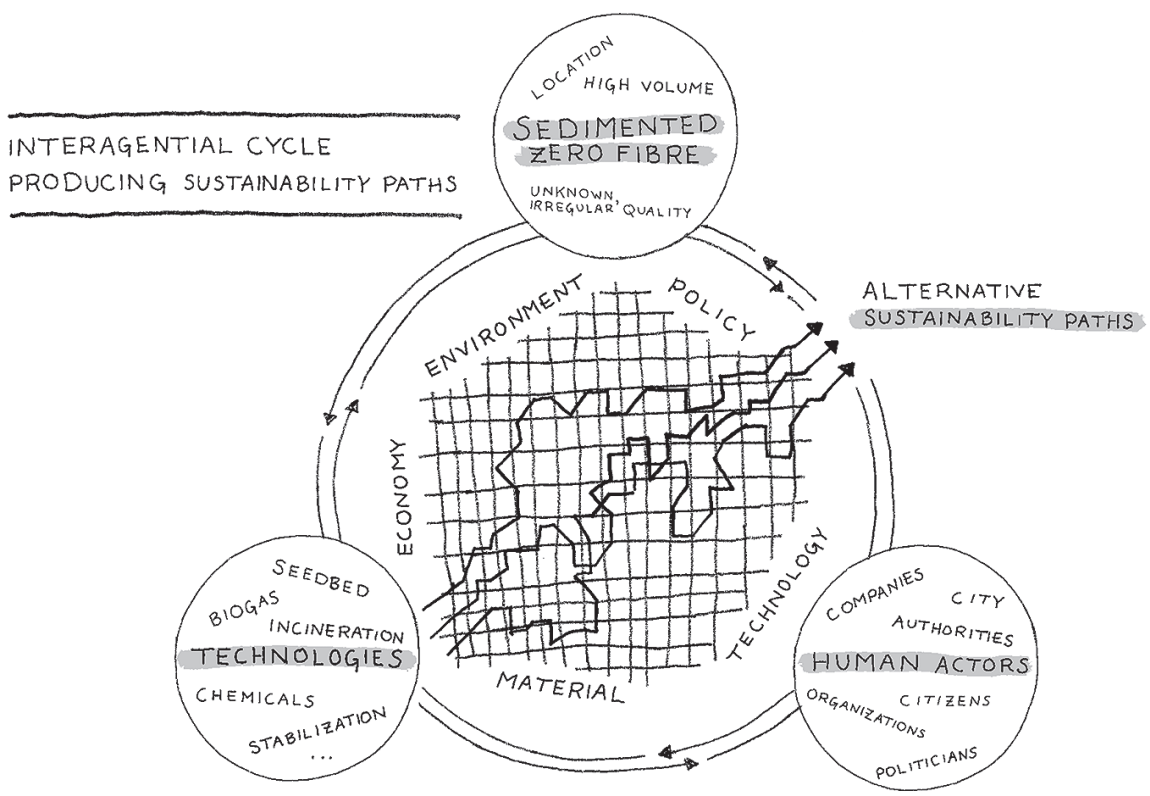

Figure $20.1 \quad$ Interagential cycle producing sustainability paths

\section{Unknown, irregular quality}

The processing technologies (e.g., the chemicals used) have been developed further since the 1980 s, and the original producers of the mass are no longer present, i.e., the origins of this particular mass are at least partly unknown. For example, some analyses have shown that the fibre includes various contaminants, such as heavy metals (e.g., $\mathrm{Hg}, \mathrm{Cu}$ ) in low concentrations.

\section{High volume}

With volume this high $\left(1.5\right.$ million $\left.\mathrm{m}^{3}\right)$, it is difficult to estimate the consistency of the whole mass of sedimented zero fibre. Different layers in the mass are expected, comprising more decomposed masses, masses with higher contaminant levels and varying amounts of foreign objects, such as big stones and sunken logs. Also, working with a mass with such a high volume takes significant resources from any company.

\section{Location}

The sedimented zero fibre lies at the bottom of Lake Näsijärvi's bay area, an important water system for the City of Tampere and its citizens. The mass is located near a groundwater basin. Moreover, planned residences in Hiedanranta are set to be built right next to the bay area. In addition, the mass has been surrounded by lake waters for decades, which is a less known environment for this kind of material. For example, the decomposition mechanisms of the mass at the bottom of the lake are not fully known, leaving it unclear as to what impacts the mass can have on the lake ecosystem and the surrounding environment with or without removal. 


\section{Zero Fibre Gets New Meanings}

The city aims to find provider(s) that could harness the sedimented zero fibre's potential as a resource in a profitable and sustainable way. The fibre's characteristics are becoming more clear and being reshaped as different specialists examine the case. Debate has emerged among various parties, which has led knowledge generation in new directions, thereby resulting in new ways to interact with and around the fibre (see the arrowed circle in Figure 20.1). For example, the researchers witnessed a situation in which a composting and fertiliser firm met each other to see whether they could process the sedimented zero fibre together. Through the stakeholders, the fibre's earlier-presented characteristics receive new meanings.

\section{Unknown, irregular quality}

It remains unclear whether the mass - a side stream from paper-processing that was disposed of legally in the lake at that time - should be classified legally as waste or a by-product. This question is highly relevant for some companies and their prospects of becoming involved in the case. Also, the possible variations in the contaminants within the mass increased uncertainty regarding its suitability for certain technological processes and their limits.

\section{High volume}

Although several masses similar to the sedimented zero fibre exist, as well as various technologies suitable for processing such high-volume masses, no provider has operated with sedimented zero fibre or with such a high-volume mass of similar materials before. In addition, the idea of processing the sedimented fibre into an end-product is an idea that is not yet commonly considered within the forest industry. The estimated possible processing time for the mass is relatively short (approximately under ten years due to the pressure of urban development) and also would demand very costly investments in facilities whose future applications would remain unclear. Thus, lots of sedimented zero fibre materials are available from the perspective of processing time, but too little from the investment perspective.

\section{Location}

Altogether, 90 per cent of the sedimented fibre mass lifted from the lake is water. Processing such a wet material or transporting it away from the area is economically inefficient and environmentally problematic and risky (considering the carbon gas emissions from the trucks and safety issues). Although it is not worth taking the mass outside the area, there is no area for processing it in Hiedanranta either. The future urban area is under construction already, and processing the mass there would require space and possibly cause odours, noise, extra traffic in the area and legal issues. In addition, acquiring the right processing permissions and assessments can take several years.

Through various parties' analysis of the fibre's characteristics, the mass receives new meanings as estimates about the time frame, costs, environmental benefits, image issues and the capacity of the possible mass-removal technologies are provided. In this process, the fibre and the modified technologies actively participate in meaning-making. The acquired, accumulated knowledge has led to new questions, tests and pilots. For example, tests that a composting firm conducted have revealed that the mass contains very few nutrients. 


\section{Reforming Technologies and Utilisation Paths}

As different stakeholders have been involved in the sedimented zero fibre case, new knowledge generation and sharing about the case have emerged. New studies and pilots that different specialists have conducted include, for example, tests regarding the stabilisation of the mass into a park soil, the biological production of chemicals from the mass, the potential of biogas production, the composting possibilities of the mass, incineration and use of the mass as a seedbed. However, there are different uncertainties related to every option, and aggregating this information and knowledge leads us to utilisation paths.

In the city's decision-making process, each of the possible recognised technologies and related utilisation paths are examined against different critical factors derived from the fibre characteristics, technological possibilities and valuations that the human actors have made. These factors are aspects that are viewed as highly relevant for decision-making regarding possible removal of the sedimented fibre. Here, the factors refer to utilisation possibilities in relation to the environment (risks related to nature, alignment with the collocated residents, sustainability, emissions), policy (the City of Tampere's role, alignment with the city strategy, possible waste status, needed permissions), technology (processing capacity, technological readiness), economy (costs, markets for end-products) and the sedimented fibre as a material (uncertainties, utilisation of the fibre's energy potential). In this interactive evaluation process, each recognised utilisation path is pushed through a web formed by the critical factors and interlinkages that the utilisation path causes between them (see the web in the middle of Figure 20.1). This way, the evaluation of each utilisation path provides alternative paths with their strengths, weaknesses, uncertainties and boundary conditions. Out of these paths, the most promising ways to utilise the sedimented fibre in an economically, socially and environmentally sustainable way can be viewed as sustainability paths to be considered in the city's final decision-making process. Three examples of potential emergent sustainability paths are presented below with some remarks.

\section{Biological conversion into chemicals}

The sedimented fibre contains different carbon compounds that can be converted biologically into valuable chemicals, such as lactic acid. It could be possible to separate these produced compounds and sell them. The preliminary estimated revenue potential of the biological conversion of the fibre into chemicals is millions of euros. However, this proposed solution's uncertainties are significant as well. The technology used remains in a piloting phase, which increases uncertainty related to the solution's technological readiness and scalability. Moreover, most of the fibre mass remains after the process, now with less value, considering that part of the carbon has been converted into chemicals.

\section{Biogas production}

Several tests have indicated that the fibre's biogas potential is significant. The biogas production technology itself is a well-tested and approved method. In addition, biogas is viewed as a sustainable energy source. The biogas process is also compatible with many residues from other previous processes, such as the aforementioned chemical production. However, biogas processing would not decrease the mass substantially, and there are no direct applications for this residue. 


\section{Composting}

As zero fibre is a bio-based material, it can be composted and used as an organic soil additive (assuming the contaminant contents do not exceed permitted levels) and even mixed with inorganic nutrients to produce fertilisers. This would align with sustainability principles. From a marketing perspective, this option includes substantial uncertainties. If the mass is to be categorised as waste, the possibilities to utilise it as a fertiliser are reduced. In addition, testing so far has indicated that the mass has low nutrient content, which directly affects its uses and upscaling of the solution.

\section{INTERAGENCY AS AN ENGAGEMENT BETWEEN HUMANS, MATERIALS AND TECHNOLOGIES}

The sedimented zero fibre case elicits several aspects of agency that usually are not discussed in sustainability research. In particular, the case questions the conventional assumption that agency, often defined as a capacity to act, is exclusively based on consciousness and intentionality.

Interagency is not a capacity that can be defined a priori, as it takes place as a result of human intervention in the material world and develops in a cycle between humans, materials and technologies. The cycle is a recursive intertwining of the social and the material, producing interagency as a relational, emergent and shifting phenomenon. The cycle entails constant reconfiguration between humans, zero fibre and technologies, thereby providing circumstances in which alternative utilisation paths for zero fibre can be created collectively (Figure 20.1). The utilisation paths developed in the process are openings to sustainability paths toward transition, given that they improve urban environments, steer the process of urban regeneration toward sustainability principles, and preferably have the potential to develop into globally used techniques and business models in the circular economy.

The zero fibre case process shows that humans alone cannot solve the problem under scrutiny. They must learn to work with zero fibre and technologies to open new possibilities to solve the problem. Continuous learning becomes possible in the interagency cycle. The following aspects are particularly important in the dynamics of interagency.

First, the zero fibre entails its material force in interactions with humans and technologies, creating constraints and enablements that momentarily steer the process. This takes place when humans are engaged with the fibre to generate new knowledge of it, when they work with technologies to make them work better within the space of constraints and enablements, and when they evaluate alternative utilisation paths. When intensity grows in these events, a recursive intertwining of the social and the material gives birth to interagency.

Second, knowledge generation of the zero fibre is extremely important in the case, but as the zero fibre becomes an object of knowledge, it only reveals parts of its characteristics (see Knorr Cetina, 1997). By making zero fibre act and respond to human interventions, and by repeating and varying these interventions, new zero fibre knowledge can be attained, i.e., gathered knowledge is based on back-and-forth movement (Latour, 1987) or the dance of resistance and accommodation (Pickering, 1995) between the human experimenter and the zero fibre. Thus, the shifting relations between humans and the material are the primary source of knowledge. Consequently, the shifting relations are the most important aspect in the enactment of interagency, not the fibre's properties (Barad, 2007; Orlikowski \& Scott, 2008). 
Third, simultaneously with knowledge generation, technologies for the utilisation of zero fibre are tested practically and improved based on experiments and learning through trial and error. Each move toward technological improvement creates new needs to acquire knowledge about zero fibre, resulting in frequent situations in which zero fibre, as an object of knowledge, never can be attained fully. Small modifications and adjustments to technologies are made repeatedly as a response to constraints and enablements set by (a) accumulating knowledge and new unknown features of the zero fibre and (b) a multi-stakeholder debate over the aforementioned critical factors and the most promising utilisation paths for managing zero fibre. These modifications and adjustments are sequences of imbrications (Leonardi, 2011) in which the social and the material become intertwined and change the routines and technologies accordingly.

The fibre case develops through material-discursive intra-actions (Barad, 2007), as it simultaneously highlights both material and discursive aspects of interagency. The material aspect refers to material things, but also to living nonhumans, as microbes are used in the experiments to gather knowledge of zero fibre's behaviour in the utilisation paths of composting and biological conversion into chemicals or methane. The discursive aspect is essential in the experiential interpretation of experiments, as well as in the reality that sustainability transitions are not only technical or economic, but also political and cultural, as well as objects of constant interpretation, debate and meaning-making.

The critical factors unveil themselves differently with each technology, implicating sociomateriality as the defining feature of this technological development (Orlikowski \& Scott, 2008). In the multi-stakeholder debate, the sedimented fibre's characteristics appear differently to different stakeholders as they are observed against each actor's perspectives. Finally, it is up to the decision-makers to evaluate the resulting options and decide on the most promising ones, i.e., sustainability paths. Although human actors will make the decisions about the removal and utilisation of the sedimented fibre, interagency remains in all alternatives and steers the final decision made for the chosen sustainability path.

Regarding leadership, the city is the leader of the zero fibre project. As the process is highly experimental and based on interagential development, overly straightforward management could destroy it. From our perspective, the leadership of this kind of sustainability process can be better understood by emphasising collective leadership, practice and materiality (see Simpson, 2016).

\section{CONCLUSION}

This chapter started by claiming that intentional agency is only one type of agency and that it has become too narrow for understanding sustainability processes. Therefore, we developed the theoretical concept of interagency, which employs dynamic engagements between humans and the material world. The central idea is that interagency is enacted in a cycle between three constituents: humans, materials and technologies. Interagency evolves in collaborative sustainability processes when new reconfigurations between humans, materials and technologies emerge during problem definition, knowledge generation and transition management. Our empirical case study demonstrates the rise of potential sustainability paths as an interagential process. 
The interagency concept responds to recent calls to take nonhuman agencies seriously in sustainability research (Gumbert, 2020) and carries significant implications for examining the material-discursive core of sustainability transitions. It clarifies the meaning of material transformations in policy processes in which paths are created for sustainability transitions in a circular economy. Circular economy solutions create value in waste and side streams, but realising the value requires constant examination of qualities, alterations and ontologies of materials, thereby activating interagential cycles. The origin of sustainability paths may lie deeply in these cycles - a topical finding for further research, practitioners and political decision-makers. The interagency concept also helps in understanding the spatial and temporal continuities in the shifting relations between humans and the material world in sustainability processes. These continuities show that previous historical development among the constituents of interagency - e.g., zero fibre's industrial, technological, hydrological, human-embodied and commercial developments in the studied case - creates conditions for future development. There are many possible avenues toward sustainability transitions, but only under certain conditions. Interestingly, the modification of technologies is based partly on global models and ideas travelling across countries and communities of practice, but local adaptation, adjustment and sociomaterial development of technologies are of most importance, as we have demonstrated. In our case, the local-global dimension can be viewed in all major developed utilisation paths.

Overall, even though our empirical case evidently has some unique features, this chapter poses a general challenge for agency research by insisting that nonhuman agency necessarily contributes to sustainability transitions. Agendas for interdisciplinary research on nonhuman agency and materiality are needed for a better understanding of transitions. For instance, research focussing on circular economy transitions has a relevant research object in the nonhuman world, but requires researchers to enter new depths in material transformations. However, there is a danger that sustainability research focussing on material or nonhuman agency easily eliminates the existence of human agency. Interagency as a conceptual research perspective avoids this problem by highlighting that both humans and nonhumans are involved in interagential cycles that give impetus to sustainability paths.

\section{ACKNOWLEDGEMENTS}

We would like to thank Marko Keinänen for helping with the interviews and data gathering. This research was funded by the Strategic Research Council, Academy of Finland, through the project 'Circular Economy Catalysts: From Innovation to Business Ecosystems' (CICAT2025) (Grant ID 320194), the European Regional Development Fund through the project 'Utilization of side streams and masses of soil in the cities' (CircVol) (Grant ID A74186), and the Academy of Finland's 'Profi4 - Urban Platform for the Circular Economy (UPCE)' research funding (Grant ID 318940).

\section{NOTE}

1. In this chapter, we put the idea of nonhuman agency into a context in which humans and nonhumans are embedded relationally in networks or assemblages and influence each other's capacity to act (see Gumbert, 2020). In this collective capacity for action, known as interagency in our vocabulary, 
we include not only humans, animals, plants and microbes, but also material things and processes, such as technologies.

\section{REFERENCES}

Barad, K. (2007), Meeting the Universe Halfway: Quantum Physics and the Entanglement of Matter and Meaning, Durham, NC: Duke University Press.

Bennett, J. (2010), Vibrant Matter: A Political Ecology of Things, Durham, NC: Duke University Press.

Corvellec, H., S. Böhm, A. Stowell and F. Valenzuela (2020), 'Introduction to the special issue on the contested realities of the circular economy', Culture and Organization, 26 (2), 97-102.

Ellen MacArthur Foundation (2014), Towards the Circular Economy: Accelerating the Scale-up across Global Supply Chains (report), Cowes, UK: Ellen MacArthur Foundation.

Fischer, L.-B. and J. Newig (2016), 'Importance of actors and agency in sustainability transitions: A systematic exploration of the literature', Sustainability, 8 (5), 476.

Geels, F. W. (2020), 'Micro-foundations of the multi-level perspective on socio-technical transitions: Developing a multi-dimensional model of agency through crossovers between social constructivism, evolutionary economics and neo-institutional theory', Technological Forecasting and Social Change, 152, 119894.

Geels, F. W. and J. Schot (2007), 'Typology of sociotechnical transition pathways', Research Policy, 36 (3), 399-417.

Geissdoerfer, M., P. Savaget, N. M. P. Bocken and E. J. Hultink (2017), 'The circular economy - a new sustainability paradigm?', Journal of Cleaner Production, 143, 757-768.

Gregson, N., H. Watkins and M. Calestani (2010), 'Inextinguishable fibres: Demolition and the vital materialisms of asbestos', Environment and Planning A, 42 (5), 1065-1083.

Grober, U. (2015), 'The discovery of sustainability: The genealogy of a term', in J. Enders and M. Remig (eds), Theories of Sustainable Development, London, UK: Routledge, pp. 6-15.

Gumbert, T. (2020), 'Materiality and nonhuman agency', in A. Kalfagianni, D. Fuchs and A. Hayden (eds), Routledge Handbook of Global Sustainability Governance, London, UK: Routledge, pp. 47-58.

Hobson, K. (2016), 'Closing the loop or squaring the circle? Locating generative spaces for the circular economy', Progress in Human Geography, 40, 88-104.

Hoffman, A. J. and S. Georg (2018), Business and the Natural Environment: A Research Overview, London, UK: Routledge.

Kivimaa, P., W. Boon, S. Hyysalo and L. Klerkx (2019), 'Towards a typology of intermediaries in sustainability transitions: A systematic review and a research agenda', Research Policy, 48, 1062-1075.

Knappett, C. and L. Malafouris (2008), 'Material and nonhuman agency: An introduction', in C. Knappett and L. Malafouris (eds), Material Agency, Boston, MA: Springer, pp. ix-xix.

Knorr Cetina, K. (1997), 'Sociality with objects: Social relations in postsocial knowledge societies', Theory, Culture \& Society, 14 (4), 1-30.

Latham, A. (2017), 'Materialities', in M. Jayne and K. Ward (eds), Urban Theory: New Critical Perspectives, London, UK: Routledge, pp. 183-192.

Latour, B. (1987), Science in Action: How to Follow Scientists and Engineers through Society, Cambridge, MA: Harvard University Press.

Latour, B. (2005), Reassembling the Social: An Introduction to Actor-Network-Theory, Oxford, UK: Oxford University Press.

Leonardi, P. M. (2011), 'When flexible routines meet flexible technologies: Affordance, constraint, and the imbrication of human and material agencies', MIS Quarterly, 35 (1), 147-167.

Meadowcroft, J. (2011), 'Engaging with the politics of sustainability transitions', Environmental Innovation and Societal Transitions, 1, 70-75.

Murto, P., S. Hyysalo, J. K. Juntunen and M. Jalas (2020), 'Capturing the micro-level of intermediation in transitions: Comparing ethnographic and interview methods', Environmental Innovation and Societal Transitions, 36, 406-417.

Orlikowski, W. J. and S. V. Scott (2008), 'Sociomateriality: Challenging the separation of technology, work and organization', The Academy of Management Annals, 2 (1), 433-474. 
Page, J. (2014), 'Disassembling and reassembling socionatural networks', in S. Locke, D. A. Sonnenfeld and D. R. Fisher (eds), International Handbook of Social and Environmental Change, London, UK: Routledge, pp. 307-318.

Patterson, J., K. Schulz, J. Vervoort, S. van der Hel, O. Widerberg, C. Adler, M. Hurlbert, K. Anderton, M. Sethi and A. Barau (2017), 'Exploring the governance and politics of transformations towards sustainability', Environmental Innovation and Societal Transitions, 24, 1-16.

Pickering, A. (1995), The Mangle of Practice: Time, Agency, and Science, Chicago, IL: University of Chicago Press.

Prieto-Sandoval, V., C. Jaca and M. Ormazabal (2018), 'Towards a consensus on the circular economy', Journal of Cleaner Production, 179, 605-615.

Robb, J. (2010), 'Beyond agency', World Archaeology, 42 (4), 493-520.

Shapiro, S. (2005), 'Agency theory', Annual Review of Sociology, 31, 263-84.

Simpson, B. (2016), 'Where's the agency in leadership-as-practice', in J. A. Raelin (ed.), Leadership-as-Practice: Theory and Application, London, UK: Routledge, pp. 159-177.

Spaargaren, G., P. Oosterveer and A. Loeber (2012), Food Practices in Transition: Changing Food Consumption, Retail and Production in the Age of Reflexive Modernity, New York, NY: Routledge.

van der Heijden, J., H. Bulkeley and C. Certomà (2019), 'Promises and concerns of the urban century: Increasing agency and contested empowerment', in J. van der Heijden, H. Bulkeley and C. Certomà (eds), Urban Climate Politics: Agency and Empowerment, Cambridge, UK: Cambridge University Press, pp. 1-20.

Wittmayer, J. M., F. Avelino, F. van Steenbergen and D. Loorbach (2017), 'Actor roles in transition: Insights from sociological perspectives', Environmental Innovation and Societal Transitions, 24, $45-56$. 